\title{
Malformation syndromes: a review of mouse/human homology
}

\author{
ROBIN M WINTER
}

From the Kennedy Galton Centre, Clinical Research Centre, Northwick Park Hospital, Harrow, Middlesex HAl $3 U J$.

SUMMARY The purpose of this paper is to review the known and possible homologies between mouse and human multiple congenital anomaly syndromes. By identifying single gene defects $*$ causing similar developmental abnormalities in mouse and man, comparative gene mapping can $\vec{\infty}$ be carried out, and if the loci in mouse and man are situated in homologous chromosome segments, further molecular studies can be performed to show that the loci are identical. This paper puts forward tentative homologies in the hope that some will be investigated and shown to $\vec{c}$ be true homologies at the molecular level, thus providing mouse models for complex纹 developmental syndromes.

The mouse malformation syndromes are reviewed according to their major gene effects. $X_{\infty}^{\infty}$ linked syndromes are reviewed separately because of the greater ease of establishing homology for these conditions.

The purpose of this paper is to review the known and possible homologies between mouse and human genetic malformation syndromes. Lalley and McKusick ${ }^{1}$ recommend the following criteria for identifying gene homologies between species:

(1) Similar nucleotide or amino acid sequence.

(2) Similar immunological cross reaction.

(3) Formation of functional heteropolymeric molecules in interspecific somatic cell hybrids in cases of multimeric proteins.

(4) Similar tissue distribution.

(5) Similar developmental time of appearance.

(6) Similar pleiotropic effects.

(7) Identical subcellular locations.

(8) Similar substrate specificity.

(9) Similar response to specific inhibitors.

(10) Cross hybridisation to the same molecular probe.

Obviously, when one is considering homologies between genes causing developmental abnormalities, it is difficult to use many of these criteria which apply to protein or DNA sequences. One must always bear in mind the point emphasised by Gruneberg $^{2}$ that "identical genes on the genetic backgrounds of man and mouse would probably differ phenotypically from each other. Conversely,

Received for publication 18 December 1987.

Accepted for publication 29 December 1987. even phenotypic similarity would be no guarantee $\stackrel{\circ}{\stackrel{\circ}{\varrho}}$ that such genes in man and mouse are homologous". $\overrightarrow{\overrightarrow{0}}$

By identifying single gene defects causing similar 3 developmental abnormalities in mouse and man, comparative gene mapping can be carried out, and if the loci in mouse and man are situated in homolo gous segments, further molecular studies can beق performed to show that the loci are identical. Thus this paper puts forward tentative homologies in the hope that some will be investigated and shown to be $\delta$ true homologies at the molecular level.

Readers are referred to the comparative geneo maps of man and mouse ${ }^{3}$ for clues about possible homologous chromosomal segments. The mouse을 malformation syndromes are reviewed according to their major gene effects. $X$ linked syndromes are reviewed separately because of the greater ease of 0 establishing homology for these conditions. Where a N mouse mutant is included in Green's Genetico variants and strains of the laboratory mouse ${ }_{0}^{4<}$ references are not given in this paper. Similarly, $\frac{\bar{D}}{\bar{D}}$ human syndromes included in McKusick's Mendelian $\stackrel{\odot}{?}$ inheritance in man $^{5}$ are not referenced, but the McKusick catalogue number is given in brackets.

\section{Methods}

Mouse mutants catalogued in standard reference 2 works $^{4}{ }^{6}$ and reported individually in published 8 reports were reviewed and compared with known? 
human malformation syndromes. The London Dysmorphology Database ${ }^{7}$ was used to search for possible human homologies from over 1700 syndromes in the database. A database of all mouse malformation mutants was also created and entries in the human and mouse databases were compared. Homologies between mouse and human chromosomal syndromes have been reported ${ }^{8}$ but these are not included in the present review.

\section{Neural tube defects and defects of the axial skeleton}

These can be divided into mutations that affect the development of the primitive streak or notochord, those which affect neural tube development, and those which affect segmentation and sclerotome differentiation. There appears to be some difficulty in deciding whether the primary defect in some mouse mutants lies in the development of the neural tube or in the primitive streak or notochord.

MUTANTS AFFECTING PRIMITIVE STREAK OR NOTOCHORD DEVELOPMENT

These include Bt-bent tail, cy-crinkly tail, Lp-loop tail, pr-porcine tail, Pt-pin tail, Sd-Danforth's short tail, tc-truncate, T-t locus, Ts-tail short, and vtvestigial tail. Many of these result in a short tail in the mouse, which is difficult to compare to man; however, several cause sacral agenesis and these may be interesting models. For example SdDanforth's short tail mice have absent or short tails, missing sacral vertebrae, and small or absent kidneys. Homozygotes have anal atresia and sometimes an absent rectum and bladder. There is similarity to caudal regression in man (McK:26875). Another mutant, srn-siren, causes a similar phenotype to sirenomelia in man. It complements, but is not allelic to, Sd.

The $\mathrm{T}$ locus, situated near the $\mathrm{H}-2$ region on chromosome 17 , is very complex and has been extensively reviewed. ${ }^{9}$ Although it has been suggested as a model for neural tube defects in man, direct homology seems unlikely because absence or shortening of the tail is usually seen, sometimes with sacral agenesis. Fellous et $a l^{10}$ described a large human pedigree segregating for various combinations of sacral agenesis, spina bifida aperta, and spina bifida occulta. Segregation distortion was seen, which is also a feature of the $T$ locus in the mouse. In addition there was some evidence of linkage to PGM3 on chromosome 6 .

Lp-looptail mice do have forms of neural tube defect including enlarged cerebral ventricles in heterozygotes and craniorachischisis in homozygotes. Bn-bent tail is an $\mathrm{X}$ linked mutation affecting the tail but with additional effects on the cranium to give an additional frontal bone. Hemizygotes and female homozygotes apparently show cranioschisis and open neural tubes in utero, so there may be some relationship to the rare forms of $\mathrm{X}$ linked neural tube defect seen in man (McK:30141).

\section{MUTANTS AFFECTING SEGMENTATION AND}

SCLEROTOME DIFFERENTIATION

The sclerotome is the mass of cells in the somite that will ultimately give rise to the vertebral cartilages. The mutants that most closely parallel human conditions are pu-pudgy, Rf-rib fusion, and $\mathrm{Mv}$ malformed vertebrae. These three are models for autosomal dominant or recessive forms of spondylocostal dysostosis in man (McK:12260, 27730). Other mutants with somewhat similar effects are Cd-crooked tail (which also manifests microphthalmia and small, absent, or non-erupted teeth in homozygotes), rv-rib vertebrae, and rh-rachiterata. The mutant am-amputated produces more severe defects including disorganisation of the vertebral column with absent lumbosacral vertebrae and rib fusion, severely shortened limbs, and craniofacial defects including cleft palate. There is thought to be a basic defect of cell adhesion. It is possible that the Jarcho-Levin syndrome in man is homologous, but this is by no means certain because am has more severe limb defects. The syndrome described by Zimmer $e t a l^{11}$ is another possible homologue.

Dm-diminutive mice have malformed vertebrae and fused ribs as well as reduced blood islands leading to macrocytic anaemia. The anaemia shows similarities to that found in Fanconi (McK:22765) and Diamond-Blackfan (McK:20590) syndromes in man. Flexed tail-f shows a similar association between vertebral abnormalities and anaemia. Tail kinks-tk causes abnormal vertebrae with the vertebral bodies ossifying from several centres and being separated from the neural arches. Undulated-un is somewhat similar.

The effects of some alleles at the dr-dreher locus show similarities to the syndrome of conductive deafness, Klippel-Feil deformity, and vaginal atresia described by Park and Jones ${ }^{12}$ (McK:14886). This may be part of the MURCS spectrum.

MUTANTS AFFECTING NEURAL TUBE

DEVELOPMENT

These mutants include ct-curly tail, which gives spina bifida and cranial defects; alleles at the Fu locus (fused, kinky, and knobbly) which is very close to the T locus; Sp-splotch which gives neural tube defects and a white belly spot and may be a defect of the neural crest; and sst-shaker short tail, which gives defects of the tail and spinal column, blebs in 
the parietal region, as well as cerebellar abnormalities and ataxia with inner ear deafness. The mutant oel-open eyelids causes open eyelids at birth, cleft palate, and sometimes cranioschisis.

\section{Limb defects}

HEMIMELIAS (LUXATE, LUXOID MUTANTS) These mutants usually cause tibial defects with preaxial polydactyly or absent preaxial toes.

Dh-dominant hemimelia, in heterozygotes, most often has absent toes, but preaxial polydactyly can also be present. The spleen is absent and the abdominal canal is shortened. The femur may be shortened and the pubic bones reduced. Ribs, sternebrae, and presacral vertebrae may be absent. $\mathrm{Hx}$-hemimelic extra toes has preaxial polydactyly of all four feet with tibial and radial hypoplasia. Heterozygotes for lu-luxoid have preaxial polydactyly of the hindfeet and homozygotes have, in addition, preaxial polydactyly of the forefeet as well as increased presacral vertebrae, ribs, and sternebrae. lx-luxate heterozygotes show preaxial abnormalities together with horseshoe kidney and hydronephrosis. Heterozygotes for lst-Strong's luxoid have preaxial polydactyly of the hindfeet, whereas homozygotes have more severe abnormalities of all four limbs.

Some of these mutants are models for Werner mesomelia in man (McK:18877), particularly $\mathrm{Hx}$, lu, and lst. There are similarities to tibial agenesis with mirror foot (McK:13575), Majewski syndrome (McK:26352), and Mohr-Majewski compound. ${ }^{13}$ Wiedemann et $a^{14}$ described a male with tibial agenesis (unilateral), preaxial polydactyly of the toes, other skeletal anomalies, and hydroureter who seems to resemble $\mathbf{l x}$.

\section{OTHER POLYDACTYLIES}

$\mathrm{Xt}$-extra toes manifests in heterozygotes with preaxial polydactyly of the fore and hindfeet with occasional postaxial polydactyly (represented by a rudimentary digit). Some alleles cause an interfrontal bone. This locus seems to be directly homologous to Greig syndrome in man (McK:17570), particularly as the loci are closely linked to TCRG in both species. Pdn-polydactyly Nagoya ${ }^{15}$ is a similar mutant which has not been tested for allelism with Xt.

Ps-polysyndactyly in heterozygotes causes syndactyly, particularly of the first and second toes in the hindfoot, and an extra digit between digits 3 and 4 with occasional postaxial polydactyly of the forefeet. This mutant seems to be homologous to syndactyly type II (synpolydactyly) in man (McK:18600).

Po-postaxial polydactyly and tu-toe ulnar are mutants which give rise to postaxial polydactyly in varying frequency according to the genetic back- ground. They are models for postaxial polydactyly types A or B (McK:17420), or perhaps the rare $\stackrel{5}{9}$ recessive types in man (McK:26345). In particular, $\overline{0}$ tu shows lack of penetrance, even in homozygotes, 흠 may be expressed in heterozygotes occasionally, and $\frac{\bar{\omega}}{\partial}$ there is evidence for modifying genes on the $\stackrel{\mathbb{\Phi}}{\propto}$ expression of the phenotype. ${ }^{16}$ Thus it appears to show great similarity to postaxial polydactyly type $B$ in man. Ed-extra digit is a further polydactyly? mutant whose effects have not been fully described. $\overrightarrow{\vec{\omega}}$

POLYDACTYLIES WITH OTHER ANOMALIES

There are a number of complex mutants causing polydactyly and eye, brain, and renal defects that $\mathrm{N}$ are associated with skin blebs during development. V These include eb-eye blebs where polydactyly is $\stackrel{p}{\circ}$ associated with anophthalmia, hypoplastic or cystic kidneys, syndactyly, and clubbed feet; fh-fetal $\frac{0}{\partial}$ haematoma and heb-head bleb where polydactyly is $\vec{c}$ associated with cloudy corneae or absent eyes; and $\subseteq$ my-blebs associated with brain abnormalities, renal agenesis, hydronephrosis, exomphalos, and syn- $\infty$ dactyly. A further mutant bl-blebbed resembles my but does not manifest polydactyly. Some of these mutants resemble Meckel (McK:24900) or perhaps hydrolethalus (McK:23660) syndromes in man, $\bar{\partial}$ particularly eb. It is of interest that my and bl, which are not syntenic, resemble one another and Fraser $\stackrel{\square}{\mathbb{Q}}$ cryptophthalmos syndrome (McK:21900). This sug- $\overrightarrow{\vec{D}}$ gests a possible aetiology and possible genetic heterogeneity in Fraser syndrome.

Hop-sterile (hop) and hydrocephalic-polydactyly (hop $^{\text {hpy }}$ ) are allelic and cause preaxial polydactyly of fore and hindfeet, hydrocephalus (in hop ${ }^{\text {hpy }}$ ), and male sterility owing to abnormalities of sperm tails. Direct homologues are difficult to identify but there are similarities to hydrolethalus (McK:23660) and acrocallosal (McK:10105) syndromes.

Fidget-fi combines preaxial polydactyly of the $\bigcirc$ hind limb often with an extra triphalangeal digit, small eyes with absence of the lacrimal glands, dislocated hips, and inner ear abnormalities. There are some similarities to the lacrimo-auriculo-dentodigital syndrome (McK:14973).

Ds-disorganisation is an extremely interesting $N$ mutation. In heterozygotes it causes almost doubling of the digits, usually on one limb only, additional limbs close to normal limbs, limb-like projections on the ventral abdomen, and papillae resembling $\mathscr{S}$ urogenital papillae or extra limbs almost anywhere on the body. Half the affected mice have cranial abnormalities. The author knows of one patient submitted to the London Dysmorphology Database with similar features (patient of Dr Dian Donnai). The child had nine toes on one foot with hypoplasia of the leg and a toe-like structure on the abdomen. 
Ts-tail short causes tail abnormalities (see above) as well as vertebral fusion, asymmetry of the length of the humerus and femur, and a triphalangeal first digit on the forefoot. There is prenatal anaemia owing to reduced blood islands in the yoke sac. There seem to be similarities to Aase-Smith syndrome (McK:20560).

\section{SYNDACTYLIES}

Isolated syndactyly in the mouse mainly involves digits 2 to 4 . jt-joined toes is a recessive mutant causing soft tissue syndactyly. sm-syndactylism is another recessive causing soft tissue fusion in the forefeet and bony fusion in the hindfeet, sometimes involving digit 1 . These mutants are models for the human forms of isolated syndactyly, although these are usually dominant. A further mutant, Dsydominant syndactylism has been reported that appears to be very similar to syndactyly type $I$ in man (McK:18590).

$\mathrm{Hm}$-hammer toe is a dominant mutation that causes syndactyly of digits 2 to 5 with flexion at the proximal interphalangeal joints. This form of syndactylism resembles that seen in Apert syndrome (McK:10120) and the very rare syndactyly type IV (McK:18620).

Limb deformity-ld is a recessive that causes complete fusion of the radius and ulna and tibia and fibula. The bones of the hands and feet are disorganised and fused. Small or absent kidneys may be found. The limb malformations appear very similar to the Cenani-Lenz syndrome in man (McK:21278), which is also recessive.

Shaker-with-syndactylism-sy causes skin or bony fusion between digits 2 to 4 on all four limbs and between the carpals and tarsals. The mice are deaf and have head tossing and circling owing to inner ear abnormalities. A direct human homologue is difficult to identify.

Os-oligosyndactylism causes syndactyly between digits 2 and 3 (sometimes 4 ) on all four limbs and reduction of the preaxial border of the limbs. Hypoplastic kidneys, leading to diabetes insipidus, are a feature. Sig-sightless mice have hydrocephalus and syndactyly of the hindfeet, most severe in homozygotes. Again direct homologues are difficult to identify, but Os shows similarities to some of the acrorenal syndromes in man (McK:10252) and also Sorsby syndrome (McK:12040).

OTHER ABNORMALITIES OF THE LIMBS

Brachypodism-bp causes hypoplasia of the middle and proximal phalanges, carpal and tarsal fusions, and shortening of the limbs. In the mouse it is autosomal recessive; a somewhat similar mutant in man, Osebold-Remondini syndrome ${ }^{17}$ is autosomal dominant.
Hd-hypodactyly causes absence of the terminal phalanx or complete hallux in heterozygotes and a single digit on all four feet in homozygotes. Homologies are not immediately obvious, but Miura ${ }^{18}$ described a mother and daughter with absent halluces and thumbs.

Oligodactyly-ol produces reduction of the postaxial digits, fusion of ribs, small spleen, and absent or horseshoe kidneys. Weyers ${ }^{19}$ pointed out that it is directly homologous to a human mutation he described (McK:19360).

Postaxial hemimelia-px causes absence of the digits on the ulna side of the limb with a reduced ulna, Müllerian defects, and an oval foramen in the scapula. It seems to be similar to the autosomal dominant syndromes described by Schinzel (McK: 18145) or Halal. ${ }^{20}$

Phocomelia-pc causes mesomelic shortening of the limbs with syndactyly and preaxial polydactyly. Extra centres of cartilage formation are seen (tarsus, deltoid crest of humerus, and on each side of the nasal capsule). The head is elongated and a cleft palate, micrognathia, and hypoplastic maxilla and premaxilla can be seen. There are similarities to Roberts syndrome (McK:26830), although this is said to be associated with a prominent premaxilla in cases where clefting is not present.

Dac-dactylaplasia causes a malformation which is very similar to autosomal dominant split hand and foot in man (McK:18360). It is of interest that manifestation of the gene may be controlled by another recessive locus, thus possibly explaining the extreme variation of penetrance. ${ }^{21}$

Ul-ulnaless causes severe reduction of the radius and ulna as well as of the tibia and fibula. It is similar to some forms of mesomelia in man, perhaps the Langer (McK:24970), Nievergelt (McK:16340), or Reinhardt-Pfeiffer (McK:19140) types. A recessive mutant causing shortening of the radius and ulna is fl-flipper arm.

\section{Bone dysplasias}

\section{OSTEOPETROSES}

Four mutants cause osteopetrosis in the mouse; these are gl-grey lethal, mi-microphthalmia, ocosteosclerotic, and op-osteopetrosis. Reversal of osteopetrosis can be brought about by transplantation of marrow or spleen cells in gl and mi, suggesting a defect of osteoclasts or other stem cells. Grey lethal is a good model for autosomal recessive osteopetrosis in man (McK:25970). There are several alleles at the mi locus, some semi-dominant. Because of the microphthalmia and dental abnormalities, there are similarities to oculo-dento-digital syndrome (McK: 16420); some alleles cause hypopigmentation, sug- 
gesting similarities to Cross syndrome (McK:25780). Osteopetrotic mice (op) do not respond to marrow transplantation and the disorder resolves with age.

OSTEOCHONDRODYSPLASIAS

The precise homology between mouse and human chondrodysplasias is difficult to assess. Certainly mutants with similar names, such as achondroplasia, are not necessarily homologous. The following appear to be true chondrodysplasias: bm-brachymorphic, can-cartilage anomaly, cho-chondrodystrophy, cmd-cartilage matrix deficiency, cnachondroplasia, de-droopy ear, Dmm-disproportionate micromelia, Dre-dominant reduced ear, hcp-hypochondroplasia, pad-paddle, sho-short head, slm-short limbed mutant, smc-spondylometaphyseal chondrodysplasia, stb-stubby, stm-stumpy. These mutants result in shortening of the limbs and trunk, sometimes with a shortened, domed skull and a cleft palate. Cartilage matrix deficiency-cmd resembles achondrogenesis type II, but there are radiological and morphological differences between the two which led Eteson et $a l^{22}$ to consider that they are not homologous. It is interesting that most chondrodystrophies in the mouse are recessive, whereas in man many are dominant. This does not necessarily mean that some of the recessive mutants in the mouse cannot be homologous to dominant mutants in man; however there do seem to be difficulties in comparing morphological and histological features. ${ }^{22} 23$

A mouse homologue for cleidocranial dysplasia (McK:11960) has recently been reported. It has been given the provisional gene symbol $\mathrm{Ccd}{ }^{24}$

A mouse mutant that may be homologous to a severe form of osteogenesis imperfecta (McK: 25940) has been described. This is fro-fragilitas ossium. ${ }^{25}$

\section{Craniofacial abnormalities}

FACIAL ABNORMALITIES

A number of mutants cause clefting of the mid-face. These are Ph-patch, Ts-tail short, and Xt-extra toes (in homozygotes). Both $\mathrm{Ph}$ and $\mathrm{Xt}$ have a central face bleb at 13 days' gestation as well as a white belly spot. The latter may indicate a neural crest abnormality. Dominant frontonasal dysplasia has been described in man (McK:13676).

The mutant far-first arch defect affects palate closure and the development of structures arising from the first branchial arch. There are similarities to human first and second branchial arch syndromes. Juriloff $e t a l^{26}$ showed that the gene was recessive on some genetic backgrounds, but dominant on other backgrounds. In the latter case the condition was asymmetrical and resembled hemi- $\overrightarrow{\vec{F}}$ facial microsomia (McK:14140).

Phocomelia-pc has been mentioned when con- 을 sidering limb defects. Homozygotes have a wide $\frac{\bar{\sigma}}{\bar{N}}$ cleft palate, absent nasal bones, and reduced maxilla $\frac{\bar{\sigma}}{\bar{\phi}}$ and premaxilla. Two mutants, Dc-dancer and Tw- $\square$ twirler, cause cleft lip and palate together with \& abnormalities of the inner ear. Two separate mutants $\vec{\circ}$ are extremely similar to agnathia-holoprosencephaly in man (McK:20265); these are j-jaw lethal and oto- $\vec{\omega}$ otocephaly. The mutant se-short ear causes reduction $\stackrel{S}{S}$ in size of the ear, reduction in body size, reduction or absence of many small bones or bony processes, i hydronephrosis, and diaphragmatic defects. There $v$ are some similarities to Fryns syndrome (McK: 22985).

CLEFT PALATE

As mentioned above, a number of chondrody- $\vec{c}$ strophies in the mouse are associated with cleft $\stackrel{一}{\rightleftharpoons}$ palate. These include cho, cmd, cn, pad, and stb. $\vec{\circ}$ Muscular dysgenesis-mdg causes abnormal development and degeneration of the skeletal muscles. $A$ small mandible and cleft palate are thought to be secondary phenomena. A number of inbred strains of mice are also susceptible to cleft palate, both spontaneously and in response to environmental agents, which may throw light on the cause of the $\stackrel{\mathbb{Q}}{\Omega}$ isolated defect in man. ${ }^{27}$

\section{EYE ABNORMALITIES}

Several genes in the mouse cause cataracts. These are reviewed by Muggleton-Harris. ${ }^{28}$ In some there may be abnormalities of one of the crystallin genes. Two loci in the mouse cause severe microphthalmia or anophthalmia without other major defects. These are ey-1. and ey-2 (eyeless- 1 and -2). They are 8 models for recessive anophthalmia in man (McK: 20690).

$\mathrm{Cm}$-coloboma and Dey-Dickies small eye cause forms of colobomatous microphthalmos which are models for forms of microphthalmos in man. The mutant dyl-dysgenetic lens appears to cause a form $\Omega$ of Peters' anomaly.

\section{Miscellaneous mutants}

Three mutants in the mouse have similarities to $\frac{\mathscr{C}}{\mathbb{C}}$ Waardenburg syndrome in man (McK:19350, $\stackrel{\oplus}{?}$ 19351,27758 ) because they manifest with combi- 7 nations of piebaldism, sensorineural deafness, and aganglionic megacolon. They are Dom-dominant $\stackrel{\Phi}{\overparen{D}}$ megacolon, ls-lethal spotting, and s-piebald (there $\mathbb{\Phi}$ are several alleles at this locus). The existence of different loci is of interest because of the evidence for heterogeneity of Waardenburg syndrome in man 
TABLE Human multiple malformation syndromes with possible mouse models.

\begin{tabular}{|c|c|}
\hline Human condition & Possible mouse model \\
\hline Aarskog syndrome & Bhd-broad headed \\
\hline Aase-Smith syndrome & Ts-tail short \\
\hline Acrorenal syndromes & Os-oligosyndactylism \\
\hline Agnathia-holoprosencephaly & j-jaw lethal \\
\hline Agnathia-holoprosencephaly & oto-otocephaly \\
\hline Ataxia telangiectasia & wst-wasted \\
\hline Anophthalmia, autosomal recessive & ey-1.2-eyeless- 1 and 2 \\
\hline Caudal regression & Sd-Danforth 's short tail \\
\hline Cenani-Lenz syndrome & Id-limb deformity \\
\hline Chediak-Higashi syndrome & bg-beige \\
\hline Cleidocranial dysplasia & Ced-cleidocranial dysplasia \\
\hline Cross syndrome & mi-microphthalmia \\
\hline Ectodermal dysplasia & cr-crinkled \\
\hline Ectodermal dysplasia & dl-downless \\
\hline Ectodermal dysplasia & Slk-sleek \\
\hline Fabry disease & Ags-alpha galactosidase \\
\hline Fraser syndrome & bl-blebbed \\
\hline Fraser syndrome & my-blebs \\
\hline Fryns syndrome & se-short car \\
\hline Greig cephalopolysyndactyly & Xt-extra toes \\
\hline Greig cephalopolysyndactyly & Pdn-polydactyly Nagoya \\
\hline Halal ${ }^{20}$ & px-postaxial hemimelia \\
\hline Hemifacial microsomia & far-first arch malformation \\
\hline Hermansky-Pudlack syndrome & ep-pale car \\
\hline Hydrolethalus: acrocallosal syndrome & hop-hop sterile \\
\hline Jarcho-Levin: Zimmer ${ }^{\prime \prime}$ & am-amputated \\
\hline $\begin{array}{l}\text { Klippel-Feil syndrome with Müllerian } \\
\text { aplasia }\end{array}$ & dr-dreher \\
\hline Lacrimo-auriculo-dento-digital & fi-fidget \\
\hline Lenz microphthalmia & Ic-eye-car reduction \\
\hline Lesch-Nyhan syndrome & $\begin{array}{l}\text { Hprt-hypoxanthine phosphoribosyl } \\
\text { transferase }\end{array}$ \\
\hline Meckel syndrome & cb-eye blebs \\
\hline Menkes syndrome & Mo-mottled etc \\
\hline Microphthalmia with coloboma & Cm-coloboma \\
\hline Microphthalmia with coloboma & Dey-Dickies small eye \\
\hline Miura & Hd-hypodactyly \\
\hline MURCS association & dr-dreher \\
\hline Neural tube defect & Fu-fused \\
\hline Neural tube defect & Sp-splotch \\
\hline Neural tube defect & Lp-loop tail \\
\hline Neural tube defect & T-t locus \\
\hline Neural tube defect & ct-curly tail \\
\hline Nievergelt: Reinhardt-Pfeiffer syndrome & Ul-ulnaless \\
\hline Ornithine transcarbamylase deficiency & spf-sparse fur \\
\hline Orofaciodigital syndrome type I & Xpl-X linked polydactyly \\
\hline Osebold-Remondini & bp-brachypodism \\
\hline Osteogenesis imperfecta type II & fro-fragilitas ossium \\
\hline $\begin{array}{l}\text { Osteopetrosis. severe autosomal } \\
\text { recessive form }\end{array}$ & gl-grey lethal \\
\hline Pelizaeus-Merzbacher syndrome & jp-jimpy \\
\hline Peters' anomaly & dyl-dysgenetic lens \\
\hline Postaxial polydactyly type A & Po-postaxial polydactyly \\
\hline Postaxial polydactyly type B & tu-toe ulnar \\
\hline Restrictive dermopathy & Er-repeated epilation \\
\hline Restrictive dermopathy & pf-pupoid fetus \\
\hline Roberts syndrome & pc-phocomelic \\
\hline Schinzel & px-postaxial hemimelia \\
\hline Sirenomelia & srn-siren \\
\hline Situs inversus & iv-situs inversus viscerum \\
\hline Situs inversus & vi-visceral inversion \\
\hline Split hand/foot & Dac-dactylaplasia \\
\hline Spondylocostal dysostosis & Mv-malformed vertebrac \\
\hline Spondylocostal dysostosis & Rf-rib fusion \\
\hline Spondylocostal dysostosis & rv-rib vertebrae \\
\hline Spondylocostal dysostosis & rh-rachiterata \\
\hline Spondylocostal dysostosis & pu-pudgy \\
\hline Steroid sulphatase deficiency & Sts-steroid sulphatase \\
\hline Syndactyly type I & Dsy-dominant syndactylism \\
\hline Syndactyly type I & jt-joined toes \\
\hline Syndactyly type II (synpolydactyly) & Ps-polysyndactyly \\
\hline Syndactyly type IV: Apert syndrome & Hm-hammer toe \\
\hline Testicular feminisation & Tfm-testicular feminisation \\
\hline Waardenburg syndrome & Dom-dominant megacolon \\
\hline
\end{tabular}

Waardenburg syndrome

Waardenburg syndrome

Waardenburg syndrome

Walker-Warburg or Meckel-Gruber syndrome

Werner mesomelia

Weyers oligodactyly

Wiedemann et al ${ }^{14}$

$\mathrm{X}$ linked anhidrotic ectodermal dysplasia $\mathrm{X}$ linked chondrodysplasia punctata

$X$ linked hypophosphatacmic rickets

$\mathrm{X}$ linked ichthyosis with hypogonadism

$\mathrm{X}$ linked neural tube defects

Is-lethal spotting

s-picbald etc

Va-varitint waddler

bh-brain hernia

lst-Strong's luxoid

ol-oligodactyly

Ix-luxate

Ta-tabby

Bpa-bare patches

Hyp-hypophosphataemia

sf-scurfy

Bn-bent tail

(two possible dominant types and a recessive form). Searle ${ }^{29}$ has also suggested that Va-varitint waddler might also be a homologue.

The mutant bg-beige shows pigment dilution and defective chemotaxis of granulocytes. It is thought to be homologous to Chediak-Higashi syndrome (McK:21450) ${ }^{33}$ Pale ear-ep has diluted pigmentation of the extremities and a platelet storage pool deficiency. Homology to Hermansky-Pudlak (McK: 20330) syndrome has been suggested. ${ }^{31}$

Two mouse mutants have interesting effects that resemble restrictive dermopathy or cocoon fetus in man. ${ }^{32}{ }^{33}$ These are pf-pupoid fetus and Er-repeated epilation. In both these mutants there is thickening of the epidermis with shortening of the limbs and tail as well as syndactyly.

Mutations at several loci cause forms of ectodermal dysplasia. These include cr-crinkled, dldownless, and $\mathrm{Dl}^{\text {slk }}$-sleek. A mouse homologue of ataxia telangiectasia (McK:20890) has been reported; this is wst-wasted. ${ }^{34}$ However, other studies have given conflicting results. ${ }^{35}$ Two mutants cause complete situs inversus ( $\mathrm{McK}: 27010)$. These are ivsitus inversus viscerum and vi-visceral inversion.

\section{X linked loci}

There are several well recognised $X$ linked loci in the mouse that are homologous to human conditions. These include Ags-alpha galactosidase (Fabry), Bpa-bare patches ( $\mathrm{X}$ linked chondrodysplasia punctata), ${ }^{36}$ Hprt-hypoxanthine phosporibosyl transferase (Lesch-Nyhan syndrome), Hyp-hypophosphataemia (hypophosphataemic rickets), jp-jimpy (PelizaeusMerzbacher disease), Mo-mottled (Menkes' disease), spf-sparse fur (OTC deficiency), Sts-steroid sulphatase (equivalent to the human enzyme), Ta-tabby (hypohidrotic ectodermal dysplasia), and xid-X linked immune deficiency (Bruton's disease).

Note that, as pointed out by Buckle et al, ${ }^{37}$ sfscurfy may be homologous to $\mathrm{X}$ linked ichthyosis with hypogonadism and is a separate locus from Stssteroid sulphatase. In man anosmia, ichthyosis, 
hypogonadism, and neurological abnormalities have been reported with steroid sulphatase deficiency, ${ }^{38}$ whereas ichthyosis and hypogonadism without steroid sulphatase deficiency has also been reported. ${ }^{39}$

A number of other $\mathrm{X}$ linked loci have possible homology. One of the more compelling candidates is Bhd-broad headed; this locus is within $1 \mathrm{cM}$ of Ta and manifests with a broad head and nose in heterozygotes with similar features and early lethality in males. Comparison of the abnormalities and of the mouse and human gene maps suggest that Bhd may be homologous to Aarskog syndrome (McK: 30540).

Ie-eye-ear reduction causes anophthalmia in hemizygotes, together with a small, thickened external ear. There are some similarities to Lenz microphthalmia, particularly the family described by Goldberg and McKusick. ${ }^{40}$

It-irregular teeth manifests with absent or reduced upper and lower incisors. Hemizygote males die before birth and in view of this, and the teeth abnormalities, incontinentia pigmenti (McK:30830) may be a candidate for homology.

$\mathrm{Xpl}-\mathrm{X}$ linked polydactyly is an $\mathrm{X}$ linked dominant mutation causing varying degrees of preaxial polydactyly of the hindfoot and urogenital anomalies (hydroureter, hydronephrosis, cystic or missing kidneys). The mutation appears to be fully dominant and hemizygous males are viable but sterile owing to undescended testes. It is difficult to find a direct human homologue for this mutant. Orofaciodigital syndrome type 1 (McK:31120) shares some common features, but is lethal in utero in human hemizygotes. The only other $\mathrm{X}$ linked polydactyly syndromes in man are Golabi-Rosen syndrome (McK:30605) and Simpson-Behmel syndrome (McK:31287) which both have postaxial polydacyly (and which may indeed be the same condition).

Td-tattered causes areas of scarring of the skin with patchy alopecia in female heterozygotes. It is a prenatal lethal in hemizygote males. Direct homology is difficult to find but there may be similarities to Goltz syndrome (McK:30560).

\section{Conclusions}

In the present paper over 80 malformation syndromes with possible mouse/human homology are reviewed. Some of the suggested homologies are very tentative and all require further study. The table summarises the possible homologies mentioned in the text.

The author would like to thank Drs A G Searle and $\mathrm{D} \mathbf{R}$ Johnson for helpful comments on the manuscript.

\section{References}

' Lalley PA, McKusick VA. Report of the committee on comparative mapping. HGM8. Cytogenet Cell Genet 1985;40 536-66.

2 Gruneberg H. Brachypodism in the mouse. Birth Defecto 1971;XIII(1):221-30.

${ }^{3}$ Searle AG, Peters J, Lyon MF, Evans EP. Edwards JH, Buckl® VJ. Chromosome maps of man and mouse III. Genomic@ 1987;1:3-18

+ Green MC, ed. Genetic variants and strains of the laborator $\overrightarrow{0}$ mouse. Berlin: Gustav Fisher Verlag. 1981.

5 McKusick VA. Mendelian inheritance in man. 7th cd. Balti $\overrightarrow{\vec{\omega}}$ more: Johns Hopkins University Press, 1986.

6 Johnson DR. The genetics of the skeleton. Oxford: Clarendor Press, 1986.

7 Winter RM, Clark RD, Ashley K, Gibbs G. A combinatoriah method for grouping cases with multiple malformations. $J$ Med Genet 1988;25:118-21.

${ }^{*}$ Recves RH, Gearhart JD, Littleficld JW. Genctic basis for $\stackrel{+\infty}{\infty 0}$ mouse model of Down syndrome. Brain Res Bull 1986;16. 803-14.

9 Klein J, Hammerberg C. The control of differentiation by the complex. Immunol Rev 1977;33:70-104.

10 Fellous M, Boué J, Malbrunot C, et al. A five-generation famil se with sacral agenesis and spina bifida: possible similarities wit the mouse T-locus. Am J Med Genet 1982;12:465-87.

1 Zimmer EZ, Taub E, Sova Y, et al. Tetra-amclia with multiple@ malformations in six male fetuses of one kindred. Eur J Pediatr 1985:144:412-4.

12 Park IJ, Jones HW Jr. A new syndrome in two unrelatec females: Klippel-Feil deformity, conductive deafness and absent vagina. Birth Defects 1971;8(6):311-7.

13 Baraitser M, Burn J, Fixsen J. A female infant with features of้ Mohr and Majewski syndromes: variable expression, a genctiळ compound, or a distinct cntity. J Med Genet 1983;20:65-7. 은

14 Wiedemann HR, Grosse KR, Dibbern H. An atlas of character $\overrightarrow{\vec{O}}$ istic syndromes: a visual aid to diagnosis. London: Wolfe Medical, 1985:296-7.

15 Hayasaka I, Nakatsuka T, Fujii T, Narusc I. Polydactyl Nagoya Pdn: a new mutant gene in the mouse. Exp Animals 1980;29:391-5.

it Center EM. Postaxial polydactyly in the mouse. $J$ Herec $1951 ; 46: 144-8$.

17 Osebold WR, Remondini DJ, Lester EL, et al. An autosomaB dominant syndrome of short stature with mesomelic shortness of limbs, abnormal carpal and tarsal bones, hypoplastic middle phalanges and bipartite calcanci. Am J Med Genet 1985;22? 791-809.

${ }^{18}$ Miura T. Congenital familial hypoplastic thumb associated with? congenital amputation of the toe. J Hand Surg 1984:9:420-2 I

19 Weyers H. Das oligodactylie-syndrom des menschen und seinc parallelmutation bei der hausmaus. Ann Pediatr (Paris) 1957 $\mathrm{N}$
189:351-70.

20) Halal F. A new syndrome of scvere upper limb hypoplasia an $\not{b}$ Mullerian duct anomalics. Am J Med Genet 1986;24:119-26응

${ }^{21}$ Chai CK. Dactylaplasia in mice: a two-locus model for developew mental anomalics. J Hered 1981;72:234-7.

22 Eteson DJ, Sillence DO, Lachman RS, Rimoin DL. The mouse skeletal mutants: models for the human skeletal dysplasias. In Normal and abnormal bone growth: basic and clinical research
New York: Alan R Liss, 1985:141-51.

${ }^{23}$ Rimoin DL. The chrondrodystrophics. Adv Hum Genet 1975;5:0 10-118.

24 Sillence DO, Ritchie HE, Selby PB. Skeletal anomalies in micos with cleodocranial dysplasia. Am J Med Genet 1987;27:75-85.

${ }^{25}$ Guenet JL, Stanescu R, Maroteaux P, Stanescu V. Fragilitå ossium: a new autosomal recessive mutation in the mouse. Hered 1981;72:440-1.

26 Juriloff DM, Harris MJ, Froster-Iskenius U. Hemifacial de 
ficiency induced by a shift in dominance of the mouse mutation far: a possible genetic model for hemifacial microsomia. J Craniofac Genet Dev Biol 1987:7:27-44.

${ }^{27}$ Slavkin HC. Congenital craniofacial malformations: issues and perspectives. J Prosthet Dent 1984:51:109-18.

2x Muggleton-Harris AL. Mouse mutants: model systems to study congenital cataract. Int Rev Cytol 1986;104:25-36.

${ }^{29}$ Searle AG. Comparative genetics of coat colour in mammals. New York: Logos Press, 1969.

30) Oliver C. Essner E. Distribution of anomalous lysosomes in the beige mouse: a homologue of Chediak-Higashi syndrome. J Histochem Cytochem 1973;21:218-28.

${ }^{31}$ Novak EK. Hui SW, Swank RT. The mouse pale ear pigment mutant as a possible animal model for human platelet storage pool deficiency. Blood 1980;57:38-43.

32 Stevenson RE, Saul RA, Collins J, Davis WM, Lanford C. Cocoon fetus-fetal encasement secondary to ectodermal dysplasia. Proc Greenwood Genet Center 1987:6:10-15.

33 Toriello HV. Invited editorial comment. Restrictive dermopathy and report of another case. Am J Med Genet 1986:24:625-9.

${ }^{34}$ Schultz LD, Sweet HO, Davisson MT. Coman DR. 'Wasted', a new mutant of the mouse with abnormalities characteristic of ataxia telangiectasia. Nature 1982;297:402-4.
${ }^{35}$ Personal communication. Mouse News Letter 1984:70:78-80.

${ }^{36}$ Happel R, Phiips RJS, Roessner A, Junemann G. Homologous genes for X-linked chondrodysplasia punctata in man and mouse. Hum Genet 1983;63:24-7.

${ }^{37}$ Buckle VJ, Edwards JH. Evans EP, et al. Comparative maps of human and mouse $\mathrm{X}$ chromosomes. Cytogenet Cell Genet 1985:40:594-5.

${ }^{38}$ Sunohara N, Sakuragawa N, Satoyoshi E, et al. A new syndrome of anosmia, ichthyosis, hypogonadism, and various neurological manifestations with deficiency of steroid sulfatase and arylsulfatase C. Ann Neurol 1986;19:174-81.

${ }^{39}$ Traupe H, Muller-Migl CR, Kolde G, et al. Ichthyosis vulgaris with hypogenitalism and hypogonadism: evidence for different genotypes by lipoprotein electrophoresis and steroid sulphatase testing. Clin Genet 1984;25:42-51.

*) Goldberg MF, McKusick VA. X-linked colobomatous microphthalmos and other congenital anomalies. A disorder resembling Lenz's dysmorphogenetic syndrome. Am J Ophthalmol 1971:71:1128-33.

Correspondence and requests for reprints to Dr R M Winter, Kennedy Galton Centre, Clinical Research Centre, Northwick Park Hospital, Watford Road, Harrow, Middlesex HA1 3UJ. 